\title{
Towards Quality and Consistency in Indian Engineering Education
}

\section{Claire Komives}

Biomedical, Chemical and Materials Engineering

San Jose State University

San Jose, CA 95192 USA

Claire.komives@sjsu.edu

\begin{abstract}
The educators of India's young engineers are embarking on the recognized standard of practice for achieving consistently top notch engineers namely, outcomes-based education (OBE). Visits to eight institutions around the country provided an interesting opportunity to learn first-hand how motivated faculty are to foster student success and implement the OBE. This paper touches on some philosophical differences between Indian and U.S. based accreditation agency parameters and an analysis of some practices in India that could result in shortcomings from an accreditation visit.
\end{abstract}

Keywords-Programme Outcomes; Engineering Education; ethics; communication skills

\section{Claire Komives}

Biomedical, Chemical and Materials Engineering

San Jose State University

San Jose, CA 95192 USA

Claire.komives@sjsu.edu

\section{Introduction}

The National Board of Accreditation (NBA) has recently modified their accreditation criteria for Indian Engineering Colleges to require demonstration of the attainment of a specific set of student outcomes that are similar to those of ABET, Inc. in the US. The assessment of program outcomes that are the attributes of graduating students is useful for programs to demonstrate to their constituencies (stakeholders), including the students, industries who hire the students, parents who pay for the education, program faculty, etc., that the graduates indeed possess the qualities advertised by the university. Effectively, the process is analogous to a company that produces a product. The quality of the product must be what the advertisements say or people will look for alternative products. The analogy of a product for sale falls short in that the education of a student is a team effort - the student plays a critical role in the process, along with the faculty of the institution, the facilities and other external influences. It is difficult to guarantee quality of a graduating student, but it is entirely possible to take the approach of continuously improving the effort to achieve 100\% top quality, and that is the strategy taken by ABET and other accreditation bodies around the world, including now also NBA in India.

There remain some fundamental philosophical differences between the NBA and ABET criteria, outcomes and policies. While NBA places numerical values on several of the criteria, such as faculty/student ratios, maximum class sizes, and 
numbers of courses under different curricular areas, the only numerical values included in the ABET Criteria are associated with the curricular areas, specifically one year of math plus basic science and one and a half years of engineering science. (One year is the lesser of 32 semester hours (or equivalent) or one-fourth of the total credits required for graduation). Thus, while the ABET approach cultivates a spirit of freedom for the faculty to assemble a program suited to the needs of the students and other constituencies, much of the decision-making in the Indian education system is pre-established by the NBA (also AICTE) accreditation commission(s). Indeed, even the wording of the ABET student outcomes provides much less detail than the descriptions of the NBA program outcomes, written to match the graduate attributes of the Washington Accord. The upshot of the ABET approach is a wide variety of curricula that allows students the opportunity to choose from a broad menu of program options across the US, at the same time given the assurance of accreditation.

\section{Observation Of Institutions}

The following descriptions are based on the observation of eight different institutions (none were IIT) in India, including those categorized as universities, colleges, autonomous and affiliated, some recently established or recently obtaining certification for granting degrees. Table 1 shows the assignment of accreditations and recognitions to the different technical institutions visited.

Table 1. Assignment of Accreditations and Recognitions from eight institutions visited

\begin{tabular}{|c|c|c|c|c|c|c|c|c|}
\hline $\begin{array}{l}\text { Accreditation/ } \\
\text { Recognition }\end{array}$ & 1 & 2 & 3 & 4 & 5 & 6 & 7 & 8 \\
\hline University & $\mathrm{x}$ & & & & $\mathrm{x}$ & & $\mathrm{x}$ & $\mathrm{x}$ \\
\hline AICTE & $\mathrm{x}$ & $\mathrm{x}$ & $\mathrm{x}$ & $\mathrm{X}$ & $\mathrm{x}$ & $\mathrm{x}$ & $\mathrm{x}$ & $\mathrm{x}$ \\
\hline NBA & & & & $\mathrm{X}$ & & $\mathrm{x}$ & & \\
\hline $\begin{array}{c}\text { NAAC A } \\
\text { grade }\end{array}$ & $\mathrm{x}$ & & & & & & & \\
\hline Affiliated & & $\mathrm{x}$ & $\mathrm{x}$ & $\mathrm{X}$ & & $\mathrm{x}$ & & \\
\hline Autonomous & & & $\mathrm{x}$ & & & & & \\
\hline
\end{tabular}

Table 2. Mapping of ABET and NBA Accreditation Criteria. (Rows are NBA)

\begin{tabular}{|c|c|c|c|c|c|c|c|c|}
\hline & 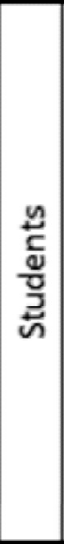 & 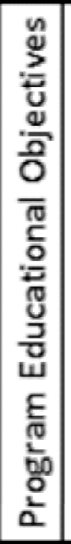 & 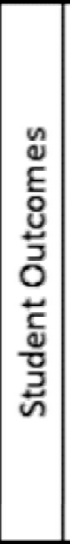 & 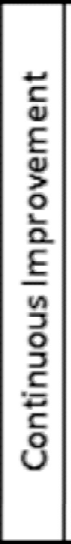 & $\begin{array}{c}\frac{E}{3} \\
\frac{\mathrm{U}}{3} \\
\frac{\mathrm{U}}{3} \\
\mathrm{U}\end{array}$ & 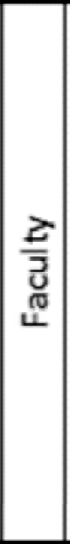 & 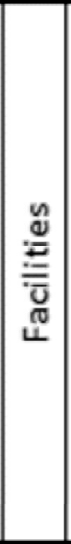 & 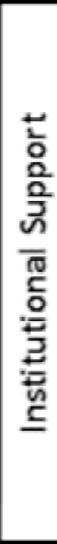 \\
\hline Institutional Mission, Vision and Programme Educational Objectives & & $\mathbf{x}$ & & & & & & \\
\hline Programme Outcome & & & $\mathbf{x}$ & & & & & \\
\hline Programme Curriculum & & & & & $\mathbf{x}$ & & & \\
\hline Students' Performance & $\mathbf{x}$ & & & & & & & \\
\hline Faculty Contributions & & & & & & $\mathbf{x}$ & & \\
\hline Facilities and Technical Support & & & & & & & $\mathbf{x}$ & \\
\hline Academic Support Units and Teaching-Learning Process & $\mathbf{x}$ & & & & $\mathbf{x}$ & & & \\
\hline Governance, Institutional Support and Financial Resources & & & & & & & & $\mathbf{x}$ \\
\hline Continuous Improvement in Attainment of Outcomes & & & & $\mathbf{x}$ & & & & \\
\hline
\end{tabular}


The descriptions are organized based on the Criterion to which the potential strengths and shortcomings would be associated. The NBA and ABET Criteria for Accreditation are listed in Table 2. Although there are slight differences between the two lists, the content can be mapped between the two sets of criteria. The ordering of the observations is by the ABET numbering but the above mapping can be used to show how the comparison with NBA criteria would be appropriate.

\section{A. Students}

At some institutions, advising of students was carried out by counselors, not by faculty. Even with high faculty-to-student ratios, interaction between faculty and students may be awkward. Advising sessions are a valuable opportunity for faculty to interact personally with students. Such sessions give students the chance to ask career advice, get suggestions about study habits and extracurricular activities. Advising by faculty also helps to break the normal communication barriers that exist between the faculty and students, by showing the students that faculty are able to take a personal interest in each student's success. Since the plan of courses in India was often fixed for each semester, which is not the case in the US, students in India may not need help to determine which courses to take next, but students appreciate the chance to discuss how the upcoming courses are important for their development.

Evaluation of student attainment of outcomes was undertaken in a variety of ways across the different institutions. It is known that assessment methods are an important aspect of instruction, and are needed for setting a high bar of student learning[1]. The types of assessment should include problem solving and knowledge transfer. Students should be challenged to apply the principles to problems they have not seen previously to determine if they are able to utilize higher order thinking skills. The problem solving skills that enable engineers to design and evaluate in their professional careers can be taught in college and are not simply innate[2]. If students are presented with a set of possible questions prior to their exam, the students can effectively memorize the solutions and the actual problem solving skills of students are not probed.

Some of the institutions had a rigid pre-set curriculum that would not allow any variation for students. Indeed, some of the institutions had no allowance for students who fail courses to repeat those courses. If a student had failed the first course of a two-course series but passed the second course, it was assumed that the student had sufficiently learned the material. This strategy suggests that the first of the two courses is not essential for the curriculum. Allowing students to continue after failing a course would violate the requirement by ABET that "The program must have and enforce procedures to ensure and document that students who graduate meet all graduation requirements." This requirement is not explicitly specified by the NBA documentation, thus allowing for students to obtain their degree without passing all of the published curricular components.

\section{B. Student Outcomes (Programme Outcomes for NBA)}

Both ABET and NBA have eleven student outcomes. There are some differences between the two sets of outcomes but most of the outcomes can be found in both lists. A mapping between the two lists was recently published[3]. Of the outcomes that are included on both lists, some of them were not incorporated into the curriculum of all eight institutions visited. The following describes some of the relevant outcomes and a summary of the level of incorporation.

The communication skills outcomes appeared to be incorporated at a developing level at most of the institutions visited. Oral communication skills are not only exercised when giving a formal presentation, but must be practiced in the engineering profession on a daily basis in technical discussions with colleagues, including both superiors and those supervised. The abilities to explain a solution strategy, or to justify a proposed product design or an experimental approach are part of daily life of engineers. In fact, one of the best ways to help students learn these skills is by incorporating teamwork problem solving through project-based or simple collaborative learning strategies in the classroom[4]. Most of the curricula offered a course on presentation skills but did not include additional assessment of communication skills in the core technical courses. Some of the universities did require students to do projects of an open-ended nature and complete with a presentation and written report, but only a few of the eight had this in place. It is necessary for students to develop their communication skills, both oral and written, in parallel with their technical development. If this is omitted from the curriculum students may not develop technical communication skills. 
Another important student outcome that is part of the set of eleven is ethics. Ethical behavior is important for every profession, but perhaps especially so for engineers because it can involve danger to individuals and society if ethics is not practiced in designing processes or structures, or taking care to dispose of waste properly, such as preventing toxins from entering rivers or groundwater, or at harmful levels into the atmosphere. In particular, specialized content should be included in the education of engineers to foster the protection of the underprivileged, who often rely on open rivers for their water supply, depend on low-cost housing and may lack the knowledge to make intelligent choices about their food and supplies options. Students cannot be expected to know about engineering ethics if it is not given a high priority in the undergraduate curriculum. There are textbooks on engineering ethics that can be used, but at a minimum one of the accepted and published codes of engineering ethics should be introduced to students in their program followed by modules and assignments on ethics that can be assessed in an ongoing way throughout the curriculum. For example, the National Society of Professional Engineers (NSPE) has published an outstanding code of ethics that includes concrete directives for ethical practice in the profession[5].

Ethics takes the form of a variety of attitudes and practices, already at the undergraduate level. Indeed, ethics is one area of philosophy that must be incorporated into one's actions and is not merely for discussion. At the undergraduate level, practice of ethics includes honesty and integrity in working together with other students, completing assignments and avoiding plagiarism. It is important that institutions impose penalties for students who cheat on tests or homework or plagiarize on written assignments. It is not sufficient that an act of plagiarism result in only a deduction in the grade, rather students should be given a failing grade either for the whole course or at least that affects their course grade substantially, and a file of infractions should be kept so that if a student commits plagiarism or cheating more than a set number of times they are disqualified from the program. Such deterrents have been in place in most educational institutions in the U.S. for some time and have been shown to be effective at rooting out cheating and plagiarism[6].

Students should be given the opportunity to design experiments and perform them. It might seem that this is not possible when the size of the classes is large or there is a shortage of equipment, but precisely in these situations students can learn to be resourceful. If student experimental experience is limited to a professor giving a demonstration, or to cookbook lab experiments, students will not learn the scientific method. This methodology is important for all branches of engineering. Engineering practice requires that new products be tested for safety and efficacy of function, and an understanding of the scientific method is essential for these sorts of explorations. Additionally, new materials must be tested for the ability to perform under stress and strain, and also the stability under normal working conditions. The use of a rubric for teaching students to design experiments is helpful for both the instructors and the students[7]. The rubric can help describe the process of experimental design, regardless of the branch of engineering. It is helpful to incorporate aspects of experimental design into the curriculum, even if a true student-designed inquiry experience is not included[8].

\section{Continuous Improvement}

Assessment of student outcomes is more and more a part of faculty activities both in the US and India. One area that can use additional development, based on the visits to institutions in India was the involvement of industry practitioners in the assessment process. For most, if not all engineering programs, industry is one of the stakeholders. Indeed, engineering is one degree that affords students good job opportunities immediately following the attainment of a bachelor's degree. Thus, it is reasonable to have professionals from industry participate at universities offering engineering degrees to help with direct evaluation of student outcomes. The evaluation process can take a variety of forms, including a poster presentation session by students of their final design projects, presentations, and other ways. The involvement of an Industry Advisory Board in program evaluation is very helpful and often results in direct involvement of industry professionals with students. Many people who work in industry are eager to help with students at universities because it can be enjoyable to work with young people on professional projects. Many companies require some community service activity of their employees as part of their professional development, and others have set aside a part of their budget to contribute to societal projects. Helping with university design projects can be beneficial for both industry and academia to this end. Without the 
involvement of industry, not only is a key stakeholder missing from the assessment process, university programs may become unbalanced toward academic outcomes and are ineffective at providing students a broad curriculum that suits their long term needs.

\section{Curriculum}

The engineering curriculum can take a variety of forms, according to the needs of the constituencies. Some aspects of the curriculum could be brought to a longer term vision considering the current student population. Students in the US are different now than they were one or two generations ago, and similar trends are anticipated to be seen around the world. Most of the engineering programs that were visited included a total of 180 units[9]. In the US, we have seen benefits in reducing the amount of content delivered in exchange for investing time in helping students learn concepts well and develop skills[10]. Engineering programs in the US likely have less than 140 units in total, including a portion dedicated to general education. The general education component is necessary for students to obtain a broad education to prepare them professionally. It is understood that the 180 units is a requirement across India, but future reductions can hopefully be revisited as one way to enable students to develop holistically through community service, work experience and other opportunities that can foster the maturation process.

One specific observation made regarding a deficit in the curriculum was a case where an internship experience could be substituted for the capstone design experience. Although internships are usually very beneficial for students, there is a great variation in them and it is difficult to assess activities that occur outside the institution. In addition, this could result in students missing a structured, assessed design experience which is essential for a complete engineering curriculum.

In the US, engineering faculty enjoy freedom in developing and modifying the curriculum based on the changing panorama of both the field and the student participants. Technology changes rapidly and new courses addressing new technological advances can attract student's interest and help prepare them for jobs in industry and graduate school. The opportunity for faculty to design a new course was almost nonexistent at the programs visited. Perhaps this situation is rooted in government policy that could be reconsidered in the future.

\section{E. Faculty}

At some of the institutions, many, or even a majority of the faculty held a Master's degree and either did not have a Ph.D. or in some cases they were working towards their doctoral degree. Although the ABET criteria does not specify the number of Ph.D. degrees there should be on a program faculty, the evaluation of faculty qualifications is included in the criteria. Specifically, program faculty must have appropriate qualifications and must have and demonstrate sufficient authority to ensure the proper guidance of the program and to develop and implement processes for the evaluation, assessment, and continuing improvement of the program[11]. The presence of the sufficient authority is borne out in the number and types of initiatives undertaken by the faculty and students that foster the attainment of the student outcomes, as well as in the consistency of student success. This level of authority may be hampered by a dearth of Ph.D. faculty. Additionally, there were some engineering teaching assignments given to non-engineers. The rigor of a degree in Physics or Mathematics may well prepare someone to teach an engineering course, but it is questionable that both engineers and non-engineers are equally able to incorporate the design aspect that is necessary in the engineering coursework.

At most of the institutions, faculty complained about the quality of the students in their programs. In fact, adults often complain about young people. However, it did appear that faculty did not view the challenge of instructing students from a heterogeneous population of backgrounds and skills as just that - a challenge. Specifically, that is the challenge for the faculty. It is important for faculty to understand that it is possible to educate the students and that the knowledge, skills and attitudes that constitute a successful engineer can be taught. This is a rewarding opportunity, and involves patience, repetition, and consistently setting a high bar for student learning. Having some younger faculty members and even some without Ph.D. degrees may be helpful for the institutions to be effective at reaching the 21 st century student. Likewise, most students respond well when they recognize the program is student-centered. Specifically, when the faculty as a team are able to take ownership of the curriculum so as to help students become effective 
engineers, students respond favorably. If faculty can be given the freedom to develop modern curricula, it may make the profession of being a faculty be attractive to a variety of people.

\section{F. Facilities}

The facilities generally were very good, and well cared for. Lower division labs and computer labs appeared to be well equipped and clean. The availability of staff to help in these labs was apparent and also administrative staff to help in the offices was at an excellent level. Many of the institutions had renovations in process or newly constructed labs, suggesting a solid investment in the programs. Some of the buildings housed modern classrooms that could be useful for teaching in cooperative learning or team formats.

Every engineering program had a required lowerdivision chemistry course. That said, not one of the institutions where the lower division lab was visited had an exemplary practice for chemical safety. The teaching labs had any of unlabeled containers, lack of secondary containment, storage of different chemicals together in the same location that could cause reaction if allowed to mix, other aspects of improper storage such as chemicals stored above eye level without secondary containment, and the like. In the US, the practice of chemical safety is not either everywhere exemplary. Industry practices have improved considerably over the past 20 years and as a result, the requirements in universities have become stricter. This will hopefully occur soon in India for the sake of teaching students how to practice chemical safety.

\section{Summary}

Indian engineering education has a world renowned reputation of producing graduates that have strong mathematical skills, but as with every educational institution, there remain opportunities for improvements. The establishment of accreditation by assessment of outcomes will enable colleges and universities to identify areas for improvement. Given the advances around the world and the networks of engineering education research and collaboration, India is well poised to become a world leader in generating consistently qualified and employable engineering graduates from a breadth of institution type

\section{References}

[1] Angelo, T.A., Beginning the Dialogue: Thoughts on Promoting Critical Thinking. Teaching of Psychology, 1995.22(1): p. 6-7.

[2] Woods, D., An Evidence-Based Strategy for Problem Solving. Journal of Engineering Education, 2000. 89(4): p. 443-459.

[3] Kotturshettar, B.B., Defining the Performance Indicators: A Framework for Program Outcomes' Attainment. Journal of Engineering Education Transformations, 2015. 28(2-3): p. 298-301.

[4] Cooper, J.L., Cooperative Learning and Critical Thinking. Teaching of Psychology, 1995. 22(1): p. 7-9.

[5] N $\quad \mathrm{S} \quad \mathrm{P} \quad \mathrm{E}$. http://www.nspe.org/resources/ethics/codeethics. 2015 [cited 2015 June 22].

[6] Martin, B., Plagiarism: policy against cheating or policy for learning. Nexus (Newsletter of the Australian Sociological Association), 2004. 16(2): p. 15-16.

[7] Anagnos, T., et al. Evaluating Student Mastery of Design of Experiment. in 37th ASEE/IEEE Frontiers in Education Conference. 2007. Milwaukee, WI USA.

[8] Du, W.Y., B.J. Furman, and N.J. Mourtos. On the ability to design engineering experiments. in 8th UICEE Annual Conference on Engineering Education. 2005. Kingston, Jamaica.

[9] AICTE Approval Process Handbook 2015-2016. 2015: p. p. 160.

[10] Woods, D.R., Problem-Based Learning for Large Classes in Chemical Engineering. New Directions for Teaching and Learning, 1996. 68(1):p. 91-99.

[11] Criteria For Accrediting Engineering Programs, E001 15-16 EAC Criteria 11-7-14, ABET, Inc. 11/1/2014: http://www.abet.org. 